\title{
INCREASING OF PRECISE ESTIMATION OF OPTIMAL CRITERIA BOILER FUNCTIONING
}

\author{
Y.M.Skakovsky ${ }^{1}$, A.V. Babkov ${ }^{2}$, E.Y.Mandro ${ }^{2}$ \\ ${ }^{1,2}$ Odessa National academy of food technologies, Odessa \\ ${ }^{1}$ ORCID: 0000-0003-4888-4469
}

Copyright (C 2014 by author and the journal "Automation technological and business - processes". This work is licensed under the Creative Commons Attribution International License (CC BY). http://creativecommons.org/licenses/by/4.0/

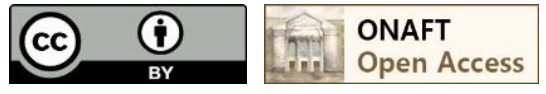

DOI: $10.15673 /$

\begin{abstract}
Results of laboratory and industrial research allowed offering a way to improve the accuracy of estimation the optimal criterion of boilers' operation depending on fuel quality. Criterion is calculated continuously during boiler operation as heat ratio transmitted in production with superheated steam to the thermal energy obtained by combustion in boiler's furnace fuel (natural gas). The non-linearity dependence of steam enthalpy from its temperature and pressure are considered when calculating, as well as changes in calorific value of natural gas, depending on variety in nitrogen content therein. The control algorithm and program for Ukrainian PLC MIC-52 are offered. The user selection program implements two searching modes for criterion maximum: automated and automatic. The results are going to be used for upgrading the existing control system on sugar factory.
\end{abstract}

Keywords

Boiler, mode optimization, criterions, calorific fuel capacity, microprocessor-based controller, program.

\section{Introduction}

Improving the running efficiency of energy-intensive steam-generating equipment in modern conditions of imported energy price rising is high priority issue. Taking into consideration the high percentage of outdated equipment fleet and limitation on financial resources for renewal of food enterprises the optimization of existing equipment operating modes is one of the key direction of increasing the profitability and competitiveness in business environment.

Carrying out self supporting theme at ONAFT Research Institute the modernization of automation systems such as DKVR-10-23 boilers that operate for a common steam header in Thermal Power Plant (TPP) for Krasilovskyi sugar factory were accomplished. Control functions are implemented in system, including boiler's operating mode optimization on the basis of proposed criterion [1, 2] also "thin client" technology for technical structure implementation were used [3].

Typically boiler unit control is based on regime maps compiled for three load modes. Efficiency coefficient as part of parameters is calculated at the beginning of operation season with reverse heat balance method. As energy-efficient modes shown in maps are defined at the beginning of operation period due to internal disturbances influence, extrema drift may occurs during the season. The availability of automatically controlled parameters in required amount for modernized automation systems allows carrying out continuous assessment of indicators, including the efficiency of boiler for entire operating period. The proposed criteria for boiler optimization [1] take into account the change in enthalpy of superheated steam for boiler operating period that allow improving the accuracy of these criteria assessment.

Currently number of enterprises' work experience shows significant changes availability in fuel quality parameters, particularly the calorific value of natural gas, compared to those declared in supplier's technical specification (Quality report). In some instances this is due to addition certain ingredients such as air or nitrogen into natural gas by supplier. This factor gives high priority considering changes in assessing the boiler optimization criterion.

The main technical solutions

The research of variation range for basic steam generation's process variables: the temperature of superheated steam, stack gases before and after economizer, feed-water; steam consumption and steam, gas, water, air pressure; underpressure in the furnace and before the exhaust fan, etc., while boiler working during operation season showed the necessarily in taking into account the possibility of indicators fluctuations that are included in boiler efficiency assessment. In work [1], a criterion similar to the efficiency of the boiler is offered, which is calculated continuously during operation by direct method, which is 
the ratio of thermal energy transferred to operation with superheated steam to thermal energy obtained by burning the furnace fuel (natural gas) in boiler:

$$
K_{\text {boiler }}=\frac{q_{\text {steam }}}{q_{\text {gas }}}=\frac{\int_{0}^{T} F_{n}(\tau) \cdot i(\tau) d \tau}{\int_{0}^{T} F_{2}(\tau) \cdot Q_{n}^{p}(\tau) d \tau}
$$

where $K_{\text {boiler }}$ - coefficient of boiler's efficiency;

$q_{\text {steam }}$ - quantity of rejected heat from the boiler to production with steam, kJ (kcal);

$q_{\text {gas }}$ - amount of supplied heat to the boiler with gas, $\mathrm{kJ}$ (kcal);

$F_{s t}(\tau)$ - instantaneous mass steam consumption, $\mathrm{kg} / \mathrm{s}(\mathrm{m} / \mathrm{h})$;

$F_{g}(\tau)$ - instantaneous volume gas consumption, $\mathrm{m}^{3} / \mathrm{s}\left(\mathrm{m}^{3} / \mathrm{h}\right)$;

$i(\tau)$ - enthalpy of the superheated steam, $\mathrm{kJ} / \mathrm{kg}(\mathrm{kcal} / \mathrm{kg})$;

$Q_{n}^{p}(\tau)$ - net calorific value of natural gas, $\mathrm{kJ} / \mathrm{m}^{3}\left(\mathrm{kcal} / \mathrm{m}^{3}\right)$;

$[0 ; T]$ - billing period (shift, day, decade, etc.) per hour.

The fact of enthalpy dependence on two variables: temperature and pressure, and the non-linear nature of these dependence were took into consideration while calculation: $i=f(t, p)$,

where $\mathrm{t}$ - temperature of superheated steam, ${ }^{\circ} \mathrm{C}$;

$\mathrm{p}$ - superheated steam pressure, $\mathrm{MPa}(\mathrm{atm})$.

Gas net calorific value that is used commonly in such assessments was determined according to gas supplying organization data or with laboratory methods.

Analyzing boiler's long operation periods [1] superheated steam temperature changes are $30-35{ }^{\circ} \mathrm{C}$, which leads to significant changes in steam's enthalpy that have to be considered evaluating the proposed criterion. Data collected with support of boiler’s operator functioning workstation №5 Krasilovskyi sugar factory TPP.

Analysis of superheated steam properties in given workspace shows that steam pressure variety influence on enthalpy changes is less than that steam temperature variety, however this effect may not be taken into account in case boiler's selfcontained operation mode, while stabilized steam pressure circuit in boiler drum. Managing group of boilers that operate on a common header there is a need taking into account those influences on steam enthalpy. The use of well-known control method based on principle of optimal load distribution between the parallel operating units is constrained with these conditions due to implementation complexity so management is based on principle of several boilers separation with extensive efficiency coefficient for operation in basic mode and one (two) for operation in adjusting mode, which achieves pressure stabilizing in generally steam collector. Thus, there is the goal of enthalpy estimating based on two embodiments: one-parameter (depending only on the temperature) and two-parameter (temperature and pressure depending).

Studies on Krasilovskyi sugar factory showed that superheated of rejected steam from the boiler to the general collector has an area of pressure change $(19,6-22,0$ atm or $1,922-2,157 \mathrm{MPa})$ and the steam temperature $\left(\mathrm{T}=340-370{ }^{\circ} \mathrm{C}\right)$ which allows to define the range values of superheated steam enthalpy in accordance with the IS - diagram and table of water and steam thermodynamic properties. The enthalpy numerical values calculation were carried out with support of computer program (is_diagramma, Osan 2002), which allows to calculate these values with high accuracy (up to the fourth decimal place, $\mathrm{kcal} / \mathrm{kg}$ ). Two decimal places is enough for our calculations taking into consideration the monitoring instruments' sets class accuracy $(0,5-1,0)$. Figure 1 shows parameters' variety operating area of superheated steam in DKVR-10-23 boiler on IS-diagram detail fragment. 
Enthalpy I, kJ/kg

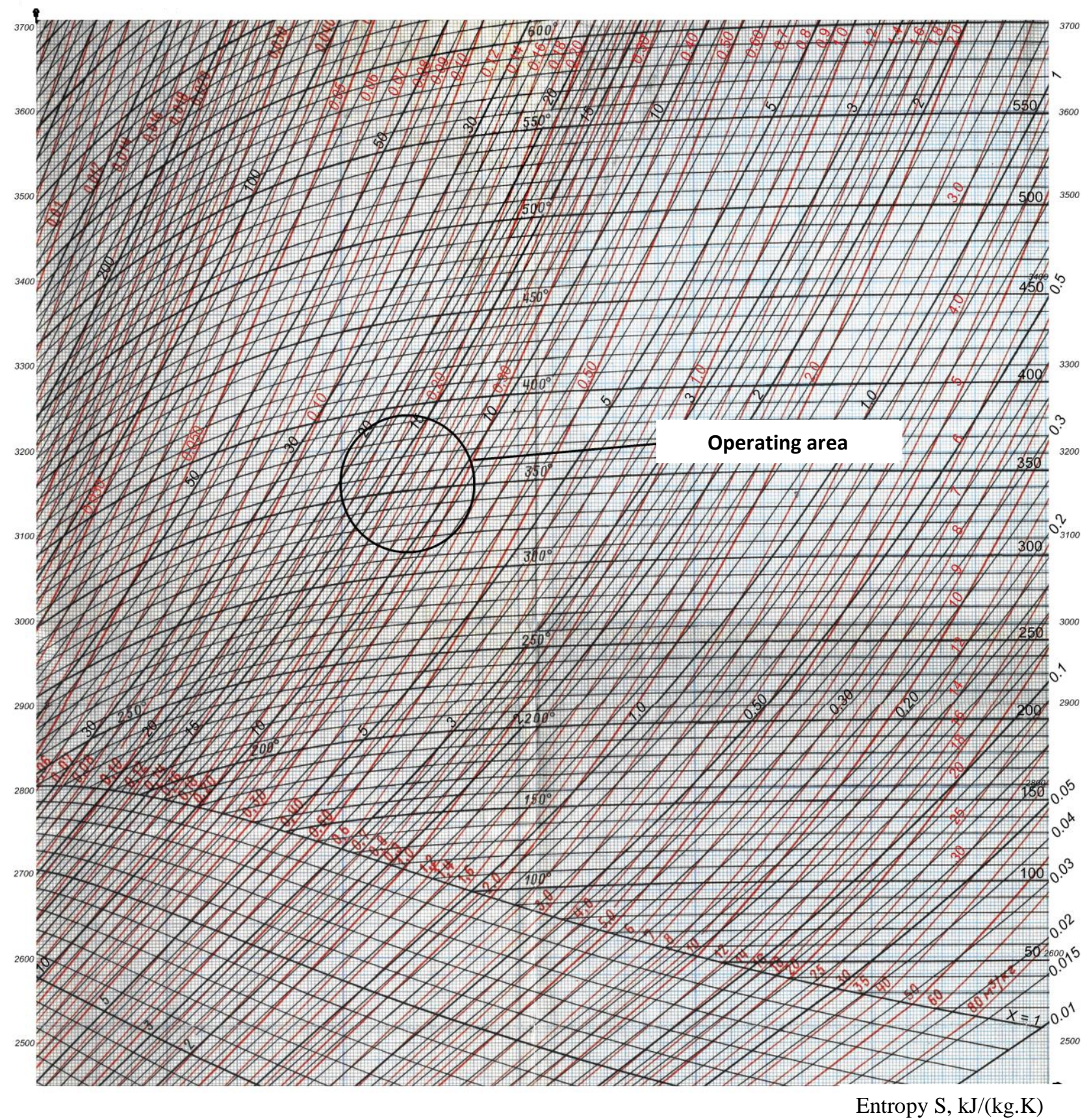

Fig. 1 - IS-diagram fragment with specified operating area of superheated steam parameters

The range of initial parameters variety (steam pressure and temperature) taking into account control sensors accuracy class were divided into pressure intervals of $0,4 \mathrm{~atm}(0,04 \mathrm{MPa})$, temperature $-1,0{ }^{\circ} \mathrm{C}$. This breakdown allows to provide enthalpy calculations with inaccuracy no more than $0,05 \%$. Thus, nonlinear dependences occurred tabular (Table 1) were laid in computing device and calculating procedures were organized in real time.

Multiplying the instantaneous enthalpy value with instantaneous mass steam consumption, integrating within the calculated time interval $[0 ; \mathrm{T}]$ the desired value amount of heat $q_{g a s}$ were calculated. Likewise, after integrating, $q_{g a s}$ value for supplied heat by gas was calculated, multiplying instantaneous volume gas consumption with its lower calorific value. The ratio of two values obtained in accordance with (1) gives the desired $K_{\text {boiler }}$ criterion value.

All calculations of criteria numerical values and procedure of its maximum search (by memorizing the extremum) were performed with a programmable controller connected to sensors, actuators and computer equipped with a SCADA-system.

The fuel consumption (natural gas consumption) $F_{g}(\tau)$ and fuel net calorific value (calorific value) $Q_{n}^{p}(\tau)$, which is used for energy calculations should be necessary to calculate $q_{\text {gas }}$ in (1). The latter $\left(Q_{n}^{p}(\tau)\right)$ may be calculated only in the laboratory with special equipment, which complicates implementation of proposed calculation method. To enable practical calculation 
implementation and automated execution $Q_{n}^{p}$ value given in fuel supplier data sheet and the same (natural gas) nitrogen content in fuel $\left(\mathrm{N}_{2}{ }^{n}\right)$ value also given, is proposed to conduct with further measuring the actual nitrogen content in gas by using gas analyzer and entering these data into controller to generate corrections in order to improve $K_{b o i l e r}$ calculations' accuracy.

Table 1 -Superheated steam enthalpy values in operating area calculation $(\mathrm{kJ} / \mathrm{kg})$

$\left(1 \mathrm{kcal}=4,18605 \mathrm{~kJ} ; 1 \mathrm{~atm}=1 \mathrm{~kg} / \mathrm{cm}^{2}=0,09807 \mathrm{MPa}\right)$

\begin{tabular}{|c|c|c|c|c|c|c|c|c|c|}
\hline \multirow{2}{*}{$\begin{array}{c}\text { Variable } \mathbf{T}, \\
{ }^{\circ} \mathrm{C}\end{array}$} & \multirow{2}{*}{$\begin{array}{c}\mathbf{P}, \mathrm{MPa} \\
\left(\mathrm{KgF} / \mathrm{cm}^{2}\right)\end{array}$} & 1,90 & 1,94 & 1,98 & 2,02 & 2,06 & 2,10 & 2,14 & 2,18 \\
\hline & & 19,37 & 19,78 & 20,19 & 20,60 & 21,01 & 21,41 & 21,82 & 22,23 \\
\hline \multicolumn{2}{|c|}{340} & 3117,27 & 3116,38 & 3115,48 & 3114,58 & 3113,68 & 3112,81 & 3111,90 & 3111,00 \\
\hline \multicolumn{2}{|c|}{341} & 3119,50 & 3118,61 & 3117,72 & 3116,83 & 3115,94 & 3115,06 & 3114,16 & 3113,26 \\
\hline \multicolumn{2}{|c|}{342} & 3121,73 & 3120,85 & 3119,96 & 3119,07 & 3118,18 & 3117,31 & 3116,42 & 3115,52 \\
\hline \multicolumn{2}{|c|}{343} & 3123,96 & 3123,08 & 3122,20 & 3121,32 & 3120,43 & 3119,57 & 3118,68 & 3117,79 \\
\hline \multicolumn{2}{|c|}{344} & 3126,18 & 3125,31 & 3124,43 & 3123,56 & 3122,68 & 3121,82 & 3120,93 & 3120,05 \\
\hline \multicolumn{2}{|c|}{345} & 3128,41 & 3127,54 & 3126,67 & 3125,80 & 3124,92 & 3124,07 & 3123,19 & 3122,31 \\
\hline \multicolumn{2}{|c|}{346} & 3130,63 & 3129,68 & 3128,90 & 3128,03 & 3127,17 & 3126,32 & 3125,44 & 3124,57 \\
\hline \multicolumn{2}{|c|}{347} & 3132,85 & 3131,99 & 3131,13 & 3130,27 & 3129,41 & 3128,56 & 3127,69 & 3126,82 \\
\hline \multicolumn{2}{|c|}{348} & 3135,08 & 3134,22 & 3133,37 & 3132,51 & 3131,65 & 3130,81 & 3129,94 & 3129,08 \\
\hline \multicolumn{2}{|c|}{349} & 3137,30 & 3136,45 & 3135,60 & 3134,74 & 3133,89 & 3133,05 & 3132,19 & 3131,33 \\
\hline \multicolumn{2}{|c|}{350} & 3139,52 & 3138,67 & 3137,83 & 3136,98 & 3136,13 & 3135,30 & 3134,44 & 3133,59 \\
\hline \multicolumn{2}{|l|}{351} & 3141,73 & 3140,89 & 3140,05 & 3139,21 & 3138,36 & 3137,54 & 3136,69 & 3135,84 \\
\hline \multicolumn{2}{|c|}{352} & 3143,95 & 3143,12 & 3142,28 & 3141,44 & 3140,60 & 3139,78 & 3138,93 & 3138,09 \\
\hline \multicolumn{2}{|c|}{353} & 3146,17 & 3145,34 & 3144,51 & 3143,67 & 3142,84 & 3142,02 & 3141,18 & 3140,34 \\
\hline \multicolumn{2}{|c|}{354} & 3148,39 & 3147,56 & 3146,73 & 3145,90 & 3145,07 & 3144,26 & 3143,42 & 3142,59 \\
\hline \multicolumn{2}{|c|}{355} & 3150,60 & 3149,78 & 3149,00 & 3148,13 & 3147,30 & 3146,50 & 3145,67 & 3144,83 \\
\hline \multicolumn{2}{|c|}{356} & 3152,81 & 3152,00 & 3151,18 & 3150,36 & 3149,54 & 3148,73 & 3147,91 & 3147,08 \\
\hline \multicolumn{2}{|c|}{357} & 3155,03 & 3154,22 & 3153,40 & 3152,58 & 3151,77 & 3150,97 & 3150,15 & 3149,32 \\
\hline \multicolumn{2}{|c|}{358} & 3157,24 & 3156,43 & 3155,62 & 3154,81 & 3154,00 & 3153,20 & 3152,38 & 3151,57 \\
\hline \multicolumn{2}{|c|}{359} & 3159,45 & 3158,65 & 3157,84 & 3157,04 & 3156,23 & 3155,44 & 3154,62 & 3153,89 \\
\hline \multicolumn{2}{|c|}{360} & 3161,66 & 3160,86 & 3160,06 & 3159,26 & 3158,45 & 3157,67 & 3156,86 & 3156,05 \\
\hline \multicolumn{2}{|c|}{361} & 3163,87 & 3163,08 & 3162,28 & 3161,48 & 3160,68 & 3159,90 & 3159,10 & 3158,29 \\
\hline \multicolumn{2}{|c|}{362} & 3166,08 & 3165,29 & 3164,50 & 3163,70 & 3162,91 & 3162,13 & 3161,33 & 3160,53 \\
\hline \multicolumn{2}{|c|}{363} & 3168,29 & 3167,50 & 3166,72 & 3165,93 & 3165,13 & 3164,36 & 3163,56 & 3162,77 \\
\hline \multicolumn{2}{|c|}{364} & 3170,50 & 3169,72 & 3168,93 & 3168,15 & 3167,36 & 3166,59 & 3165,80 & 3165,00 \\
\hline \multicolumn{2}{|c|}{365} & 3172,71 & 3171,93 & 3171,15 & 3170,37 & 3169,58 & 3168,82 & 3168,03 & 3167,24 \\
\hline 366 & & 3174,91 & 3174,14 & 3173,36 & 3172,58 & 3171,80 & 3171,04 & 3170,26 & 3169,48 \\
\hline 367 & & 3177,49 & 3176,35 & 3175,58 & 3174,80 & 3174,03 & 3173,27 & 3172,49 & 3171,71 \\
\hline 368 & & 3179,32 & 3178,56 & 3177,79 & 3177,02 & 3176,25 & 3175,49 & 3174,72 & 3173,94 \\
\hline 369 & & 3181,53 & 3180,77 & 3180,00 & 3179,24 & 3178,47 & 3177,72 & 3176,95 & 3176,18 \\
\hline 370 & & 3183,73 & 3182,97 & 3182,21 & 3181,45 & 3180,69 & 3179,94 & 3179,18 & 3178,41 \\
\hline
\end{tabular}

Nitrogen is selected as the largest air component (approximate volume percentage is $78 \%$ ).

The fuel (natural gas) technical specification gives its percentage values for example: methane $\left(\mathrm{CH}_{4}\right)-92 \%$, ethane $\left(\mathrm{C}_{2} \mathrm{H}_{6}\right)-3,9 \%$, propane $\left(\mathrm{C}_{3} \mathrm{H}_{8}\right)-11 \%$, butane $\left(\mathrm{C}_{4} \mathrm{H}_{10}\right)-0,4 \%$ pentane $\left(\mathrm{C}_{5} \mathrm{H}_{12}\right)-0,1 \%$, nitrogen $\left(\mathrm{N}_{2}\right)-1,6 \%$, carbon dioxide $\left(\mathrm{CO}_{2}\right)-0,1 \%$. Thus, excluding a small fraction of $\mathrm{CO}_{2}$ gases, which combust and generate heat are: $(100-\% \mathrm{~N} 2) \%$. If the actual nitrogen content is increased with respect to passport the actual fuel calorific value decreases, respectively, compared with certified value.

The current $K_{\text {boiler }}$ value is calculated in controller with entered data in real-time according to such dependence:

$$
K_{\text {boiler }}=\frac{q_{\text {steam }}}{q_{\text {gas }}}=\frac{\int_{0}^{T} F_{n}(\tau) \cdot i\left(T_{n}, P_{n}, \tau\right) d \tau}{\int_{0}^{T} F_{g}(\tau) \cdot Q_{n}^{p}(\tau)\left\lceil\frac{100-\% N_{2}^{f}(\tau)}{100-\% N_{2}^{n}(\tau)}\right] d \tau}
$$

where $\% N_{2}^{n}$ - nitrogen content value in natural gas, given in fuel technical specification (Quality report), \%; $\% N_{2}^{f}$ - nitrogen content value in natural gas, measured by a gas analyzer, $\%$. 
Thus, if technical specification and measured nitrogen content are the same (air in the gas supplier is not added) then technical specification value $Q_{n}{ }^{p}$ is used in calculation. If as a result of the addition air in the fuel actual nitrogen content exceeds technical specification, correction in shares is automatically calculated, which allows to increase the accuracy of $K_{b o i l e r}$ calculations and as a consequence gives better definition to "gas-air" correlation coefficient optimal value, which is used as set up in boiler control circuit ("combustion efficiency" loop).

The proposed effectiveness method is confirmed by a simple example, if in fuel technical specification the value of $\% N^{n}=1,5 \%$ and according to gas analyzer $\% N_{2}^{f}=3,5 \%$ then $Q_{H}{ }^{p}$ values given in technical specification decreases in (100 $\left.\% N^{\phi}\right) /\left(100-\% N^{n}\right)=(100-3,5) /(100-1,5)=96,5 / 98,5=0,9797$ times. That shows the possibility of more accurate calculation with more than $2 \%$ for optimal $K_{\text {boiler }}$ value.

To calculate $q_{\text {steam }}$ the boiler capacity $F_{n}$ is to be measured and enthalpy value to be calculated, which changes during boiler operation, depending on steam temperature and pressure. The steam enthalpy is calculated in controller according to data measured by temperature and pressure sensors of superheated steam, based on laid in controller dependence according to data got in water and water steam properties tables or a well-known «is - diagram» computer program may be used. Therefore, $K_{\text {boiler }}$ calculation accuracy significantly increased. At the appropriate time interval an extremum is to be searched (maximum $K_{\text {boiler }}$ ). At that time, when there the corresponding extremum $\kappa_{\text {кот }}^{\max }$ is been calculated and the values of this fuel (gas)- air $K c_{i}{ }^{o p t}$ flow ratio coefficient is fixed (or input furnace pressures ratio), then control of boiler operation is conducted due to this

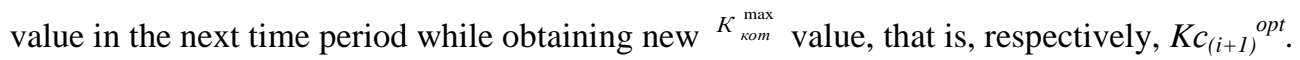

Therefore, the internal perturbations inherent to boiler units (heat transfer coefficient changes) are taken into account and that lead to unsteadiness in steam parameters of production process and in case of adding an air in natural gas by supplier a technical specification's correction of value for lower fuel heat combustion is conducted, which allows to define $K_{\text {boiler }}$ calculations more exactly.

Program of test procedures realization for $K_{\text {boiler }}$ evaluation, its extremum (maximum) search and the usage of found optimum «fuel-air» ratio coefficient in air supply control circuit for boiler's burners is designed in FBD-like editor that is Alpha for MIC-52 controller program creating (by MICROL company) and is shown in fig. 2 (program debug mode is powered).

Algobloks (AB), AIN (05), 1-3, 24-27 are used in that program for inputting and pre-processing sensors signals and therewith the established limit values of variables changes provide the formation for corresponding logic outputs to listed $\mathrm{AB}$ $(02,03)$ signals that are equal to figure of one in case of reaching these limits, which allows to treat them according to the scheme of logical "OR" in the SCADA system, to generate a message about the unreliability of the calculations performed automatically. In this case, until debugging control is carried out according to the latest clean data. Digital input AB that is DIN (06) 39 is used for program external management allowing, if necessary to put a stop to AB timer TIMER (38) 38 or carrying out program restart. Similar function is performed by AB dSET (83) 41, when program controlling with attached screen form.

AB LIMIT (34) 4-11 provide branching calculation algorithm in occurring the signal by superheated steam pressure in one of the ranges (columns in table 1) installed in these $\mathrm{AB}$ (from 0 to $100 \%$ percentage). To calculate the enthalpy as temperature function the LINEAR AB (52) 14-21 serves that are installed in each branch of calculation algorithm, where a piecewise linear approximation of the nonlinear enthalpy dependence on temperature (the lines in each table 1 column) is implemented. Each calculated algorithm branch contact entering to appropriate AB LINEAR (52) is provided by the joint work of AB IF (80) 12 and MUX (36) 22. Technical specification of natural gas and contained nitrogen net calorific values are entered by AB SP (53) 29, 30. The correction calculation that includes variety in natural gas quality is carried out in AB SUMM (13) 31, 32 and DIV (14) 33.

The AB DIV (14) 28 coefficient current value of air and gas pressures ratio entering the burners is calculated. The program calculates the inverse ratio $K_{c}^{o}=P_{v} / P_{g}$, which allows to use while formatting task for the air pressure regulator (as pressure ratio controller analogue) $\mathrm{AB}$ Multiplication MUL (12) 47, 56 instead AB dividing in order to minimize the probability dividing on zero. In addition, the program assure the availability of delay in controlled object channel «gas pressure - steam pressure - steam consumption» by AB AVRG (32) 50. An implementation analysis of these variables of boiler automation systems operation on previous seasons archive data makes possible to estimate this delay as close to 55 - 60 seconds values.

The program calculates evaluation criterion integrated in AB DIV (14) 36 by dividing the integrated in AB INTEGR (17) 23 and 37 current values amount of heat transmitted to consumers $q_{\text {steam }}(t)$ and incoming with gas $q_{\text {zas }}(t)$. This assessment, as well as other indicators and data is transmitted to the SCADA system, which used it for visual presentation, archiving and further technical managers' analysis. Calculating period (integrating) may be selected for shift (12 hours), days (24 hours) as shown in the program, or for a longer period.

To implement the search maximal value criterion and its corresponding optimum value of «air-fuel» ratio coefficient AB extremum extraction EXTREM (33) 43, AB memorizing MEM (43) 44, 45 are used that are driven with AB OSC (40) monostable trigger circuit 51 and AB dividing DIV (14) 28, 42. Since criterion variety may be caused by components lowfrequency (parametric perturbations) and also high-frequency that are associated with fluctuations in flow, steam, gas, air, 
pressure - filtering signals as in $\mathrm{AB}$ extremum extraction 36 and for «air - fuel» current values of correlation coefficient in $\mathrm{AB}$ FILTER (50) 46 are essential to use.

At the moment of maximum detection at a time equal to the controller cycle time - digital signal dMAX=1on a discrete output dMAX is formed, which passed through AB monostable trigger circuit OSR (40) 51 is supplied to AB memory 44, 45, which records criterion maximum value and the corresponding optimum «air-fuel» ratio coefficient value.

The program provides two modes: automatic and manual.

The first one involves analysis by a competent specialist in ratio graph $K_{b o i l e r}=f\left(K_{c}^{o}\right)$ obtained by the SCADA system in criterion maximum values for representative period (shift, day or more), and, in the case of criterion global maximum detection of corresponding $K_{c}{ }^{o}$ value. Found optimal value is used as basic in regulation circuit of air and gas pressure ratio for the next time interval (shift). The criterion dependence from «air-fuel» ratio coefficient (figure 3) has form as shown in [1]. The ordinate shows the criterion values in percentage.

Setting to regulator the air pressure AB PID (60) 64 is formed, as a multiplication $P_{\text {air }}^{\text {bas }}=P_{\text {gas }} \cdot K_{c}^{o p t}$ in AB SP (53) 53 and MUL (12) 56. The controller output is connected to AB AOT (08) 49 analog output, so its signal goes directly to frequency converter (FC) input of air blower drive on burners.

Automatic mode allows cyclic operation on days interval (24 hours), the search and memorization of found local criterion maximum and its corresponding $K_{c 1}^{o p t}$ value for first shift interval (12 hours), compared with the found local criterion maximum on the second shift, selection one of them that is more and transfer $K_{c}^{o p t}$ value corresponding to more to the correction controller unit AB SUMM (13) 48. This algorithm is implemented using AB counter COUNT (39) 54, switches by number MUX (36) 55, 59, maximum selection MAX(31) 57, delay blocks AVRG (32) 58, 60 with time settings T.DL=12 hours (shift) that in simulation bench studies are scaled, as well as other time settings, T.DL=12 minutes.

In case of absence in detection the maximum test for the base period controller works with initial indicators (the last optimal) without correction. Transmission terms to correct unit for initial indicators are fact of activation an automatic optimization by setting (using screen form) in AB dSET (83) 62 of dSET = 1 parameter and finding the basic optimum $P_{6}^{\text {bas.opt }}$ values in range: $P_{w}^{\text {bas.opt }} \in\left[\left(P_{w}^{\text {bas. init }}-15\right) ;\left(P_{w}^{\text {bas. init }}+15\right)\right]$ whose ambits 


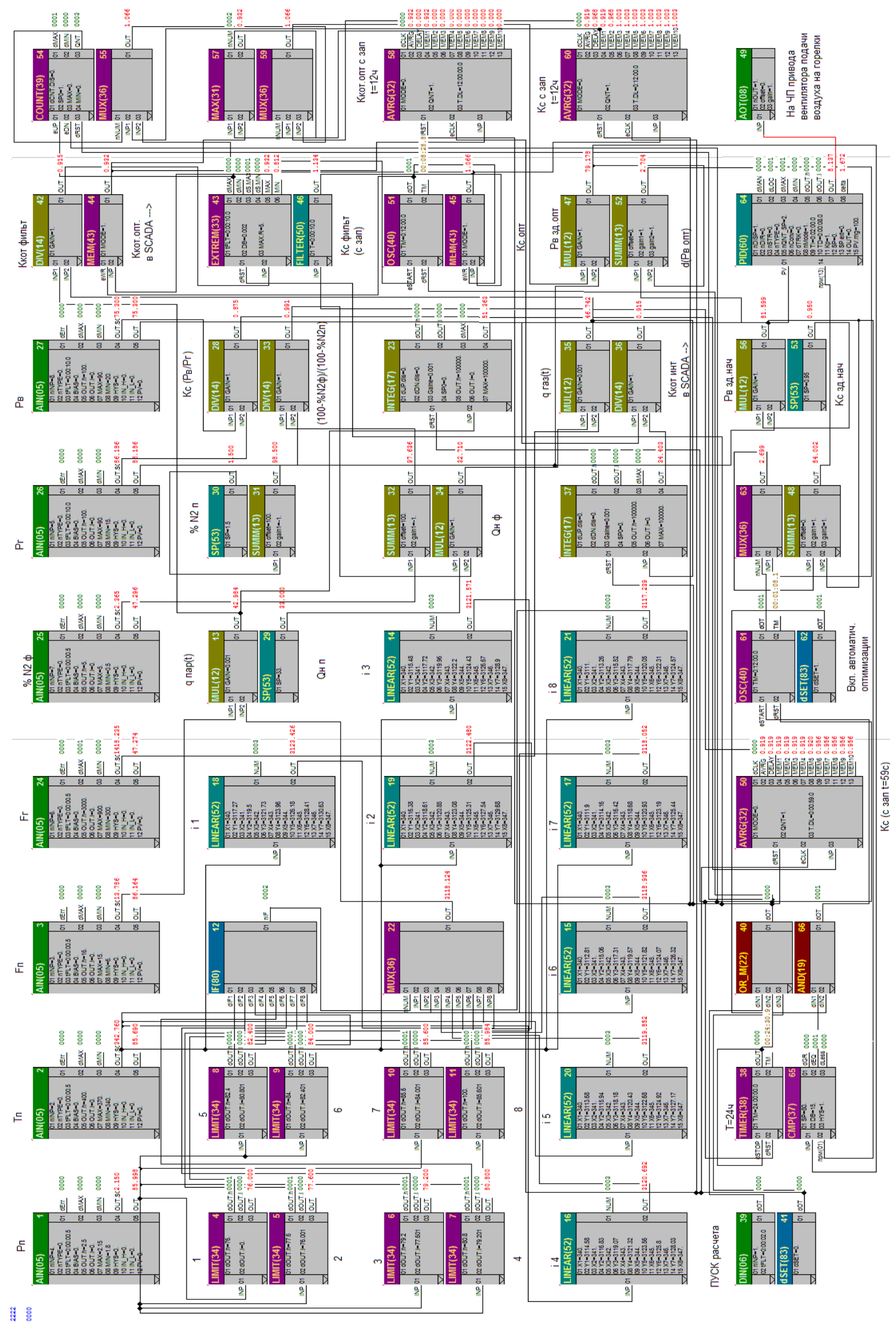

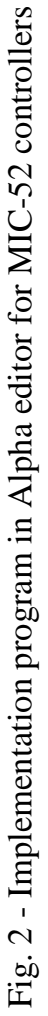


Specified to implemented on previous operation seasons of boilers' information system. Joint comparator operation AB CMP (37) 65, logical «AND» AND (19) 66, the monostable trigger circuit OSC(40) 61 and switcher by number MUX(36) 63 ensure the implementation of described algorithm.

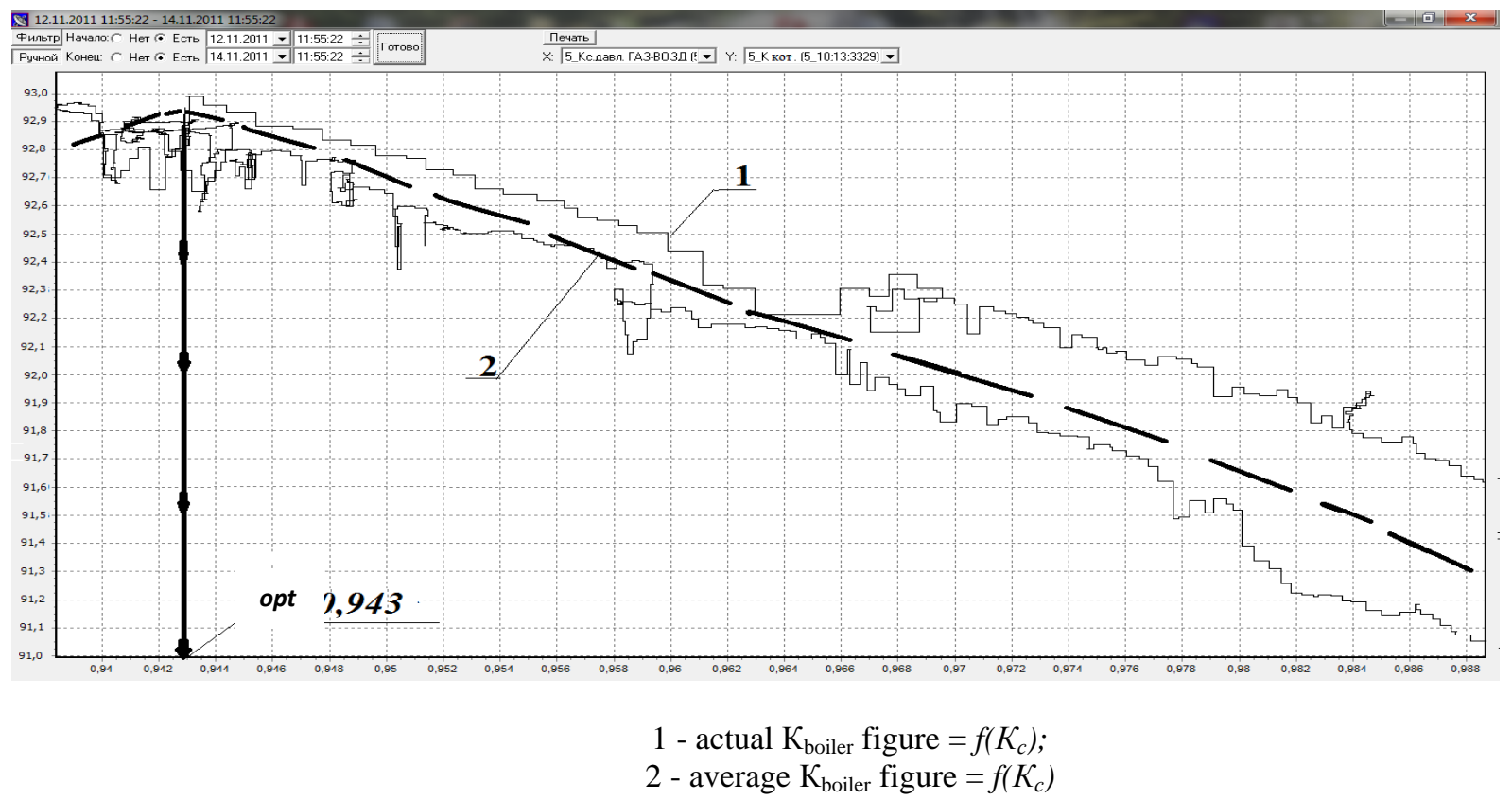

Fig. 3 - Criterion dependence from «air-gas» ratio coefficient

Auto mode does not involve global criterion maximum search within 12-hour shift, but provides selection of one greater that was found between two adjacent shifts. However, it should be mentioned that the availability of several criterion maximum found during the shift indicates the need to increase (DB) AB EXTREM(33) 43 insensitivity zone as boiler internal perturbations is quite inertia.

Studies conducted on the specialized stand containing a programmable controller MIC-52, manual analogue and discrete setting devices, interface conversion unit BPI-52 and a computer equipped with necessary software: $\alpha$ editor, SCADA-system INDEL (INFOTEHPROM enterprise development, c. Poltava) confirmed program efficiency. Input signals ranges of change is determined based on archive variables stored in workers' workstations computers on TTP plant. Program fine-tuning adjustment and $\mathrm{AB}$ parameters refinement are going to be conducted at plant during the 2016-2017 years for system operation season.

\section{Conclusions}

As a result of laboratory research and in-process testing as part of modernized boiler section control system, a method for efficiency increasing based on continuously evaluated indicators of equipment operation use was implemented. To improve the accuracy of drum-type boiler' criteria optimality evaluation in variety fuel quality, a method proposed, which provides technical specification of lower heat combustion values automatic correction. A program is designed in Alpha editor similar to FBD-editor in order to implement this method on controllers operating in TTP Krasilovskyi sugar factory.

\section{Referenses}

[1] Skakovsky Y. M. Primenenie innovacionnykh resheniy pri modernizacii sistemi avtomatizacii kotloagregatov v TEC saharnogo zavoda/ Y. M. Skakovsky, V. D. Vitvitsky, A. V. Babkov//Nauk. pr. ONAHT/Ministerstvo osviti Ukraini.Odesa: 2012.- Vip. 42, Tom 2, S. 505-510.

[2] Patent na korisnu model №63774 Ukraine, MPK, Sposib avtomatichnogo keruvannia, kontrolu, zakhistu ta signalizacii kotloagregatu/ V. C. Iluca, Y. M. Skakovsky, V. D. Vitvitsky; ONAHT.-opubl.:25.10.2011, Bul. №20, 2011 r.-6 s.

[3] Skakovsky Y. M. Vikoristannia tekhnologii «tonkikh klientiv» dlia stvorennia informaciynoi sistemi kotelnogo viddilennia v TEC cukrozavodu/ Y. M. Skakovsky, A. V. Babkov//Avtomatizacia tehnologicheskih i biznes-procesov.-- Odessa: 2014 - №17.- S. 8-10. 